\title{
LAS TRANSICIONES A LA DEMOCRACIA EN LAS AULAS UNIVERSITARIAS: EL PAPEL DE LA HISTORIOGRAFÍA. CHILE Y ESPAÑA EN PERSPECTIVA COMPARADA ${ }^{12}$
}

\author{
TRANSITIONS TO DEMOCRACY IN UNIVERSITY CLASSROOMS: THE
}

ROLE OF HISTORIOGRAPHY. CHILE AND SPAIN IN COMPARATIVE

PERSPECTIVE

\author{
Yurena González Ayuso ${ }^{3}$ \\ Universidad Autónoma de Chile \\ DOI: 10.17533/udea.tempus.n7a05
}

\section{Resumen}

El presente artículo se propone identificar cómo se imparte la historia de las transiciones a la democracia de España y Chile en las universidades de cada uno de estos países. El objetivo no es otro que comprender la articulación y las características de la evolución y desarrollo de la historiografía de esta temática, entender su extensión, sus limitaciones y, por supuesto, su contenido, a través de la identificación de su implementación en las aulas universitarias. La identificación y resolución de las problemáticas que han ido surgiendo para conseguir este objetivo nos han aportado también la percepción y la comprensión del funcionamiento universitario de ambos países, así como la identificación de la conexión entre historiografía profesional y especializada con la comunidad universitaria en formación. Además, este trabajo se presenta de forma comparativa y entendiendo globalmente los dos casos seleccionados.

Palabras clave: historiografía, universidades, transiciones democráticas, Chile, España.

\section{Abstract}

This article identifies the strategies of teaching the history of transition towards democracy in Chile and Spain at the level of university education. Hence, the objective of this paper is to understand the characteristics of the evolution and development of historiography on this issue through a comparison that focuses on contents, extension as well as limitations through their

\footnotetext{
${ }^{1}$ El presente artículo es la extensión y desarrollo de la ponencia realizada por la autora en el XVIII Congreso Internacional de AHILA celebrado en Valencia en septiembre de 2017, al cual se asistió gracias al apoyo y soporte de la Universidad Autónoma de Chile.

2 Artículo recibido el 15 de febrero de 2018; aprobado el 30 de marzo de 2018

${ }^{3}$ Investigadora en formación y doctoranda de la Universidad Autónoma de Chile y de la Universidad de Alcalá (España). Se encuentra realizando su tesis doctoral sobre la historiografía de las transiciones democráticas de Chile y España. Es licenciada en Historia por la Universidad de Alcalá (2013) y Magíster en América Latina y la Unión Europea: una cooperación estratégica por la misma Universidad (2014). Correo: yure.ga90@gmail.com
} 
respective university teaching methodology. Attempting to answer these key questions will finally lead to a deep and new insight into the art of professional historiography in general and its links and connections with more basic university levels specifically. Due to the comparative approach, this article will also add to a more global understanding of general struggles that come with teaching rather current historical processes.

Key words: historiography, university, transitions to democracy, Chile, Spain.

\section{Introducción}

Los procesos de transición a la democracia, como iniciadores y fundadores del sistema político democrático, han suscitado una abundante bibliografía y literatura especializada. La cantidad de autores que han dedicado sus páginas a escribir y ampliar la discusión sobre los procesos de formación de las nuevas democracias actuales es muy numerosa. Y no es para menos. Un acontecimiento tan crucial como es la transformación de un sistema político autoritario y la inauguración de una democracia, como los que se vivieron a finales del siglo $\mathrm{XX}$, debe ir acompañado de una gruesa amalgama de ideas fuerza que se extiendan por toda la sociedad, sean aceptadas y se mantengan como verdaderas el más largo tiempo posible. La necesidad de mantener encendida la llama de la esperanza en la democracia y de la confianza en el sistema instaurado, hace que la comunidad académica se haya interesado desde el inicio en celebrar los logros del proceso transicional, o al menos a priori, en no señalar los desaciertos.

La labor de la historia ha sido hasta ahora ampliar el relato y las ideas fuerzas que lo sustentaban han sido completadas; poco a poco se ha ido profundizando en el conocimiento que se tenía sobre el proceso y se han ido generando algunas voces críticas. Se han ilustrado algunos vacíos propios del pasado con más conocimiento, arrojando luz a ciertas incógnitas y preguntas que han surgido con el paso del tiempo. La variedad de perspectivas y disciplinas es inmensa, tanto es así que se ha dado forma a un único y exclusivo campo de estudio para abordar estos procesos: la transitología ${ }^{4}$. Se trata del intento de la politología de agrupar los estudios sobre transiciones en un único grupo genérico que dé respuestas generalizadas y desarrolle análisis lo más amplios posibles con el máximo número de casos. ${ }^{5}$ Este anecdótico proceso académico es interesante identificarlo porque confirma que ya existe una disciplina, o al menos, subdisciplina especializada, que se ha preocupado de explicar estos procesos. Por tanto, cuál es entonces el

\footnotetext{
${ }^{4}$ Alain Rouquié, A la sombra de las dictaduras. La democracia en América Latina (Buenos Aires: Fondo de Cultura Económica, 2011), 114.; Álvaro Soto Carmona, "Ni modélica ni fracasada. La transición a la democracia en España: 1975-1982", Índice Histórico Español, n. 125 (2012): 119.

${ }^{5}$ Soto Carmona, "Ni modélica ni fracasada", 119.
} 
papel de la historia. Así pues, nos preguntamos ¿cómo se ha comportado la disciplina histórica a la hora de estudiar y tratar los procesos de transición democrática?

Una vez que la politología se resignó a protagonizar los estudios sobre las transiciones, —una vez que éstos pasaron a la historia—, los historiadores se acercan temerosos al estudio del pasado reciente, encontrándose con herméticas conclusiones politológicas y conceptos básicos ya delimitados para denominar y explicar los entresijos de los procesos ${ }^{6}$. La historia tuvo que derribar algunos mitos, generar algunas discusiones, pero también acompañar la tendencia y sustentar las ideas fuerza de las transiciones con el conocimiento verdadero e inequívoco que aporta la historia (positivista).

Como bien sabemos los historiadores no tan positivistas es complicado acercarnos al conocimiento completo e inequívoco del pasado, una realidad que ha dejado de existir en su totalidad $^{7}$. Por eso, a pesar de los logros que se han conseguido desde la historia para ampliar el conocimiento del pasado reciente, debemos prestar atención siempre y no olvidar en ningún momento el hecho de que existen muchos pasados, muchos relatos y muchas perspectivas sobre el mismo acontecimiento; y como tales, como acontecimientos pasados, los procesos transicionales que nos trajeron la democracia también son múltiples y plurales, y no forman parte de ningún mito. La riqueza de la historia debería residir en la pluralidad de perspectivas y visiones y no en el intento de imponer una, aunque sea a través de la defensa de argumentos de cientificidad u objetividad. Pero ¿sucede lo mismo al enseñar e impartir este proceso histórico crucial para entender nuestro presente? Esta es la pregunta clave que queremos desentrañar en el presente trabajo.

\section{Planteamiento de una problemática}

La principal premisa desde la que partimos es que, en las Universidades, son el lugar en el cual se forma y se enseña a los futuros profesionales de la historia. Se trata de una institución que, por un lado, forma a los profesores de historia que impartirán el conocimiento del pasado en las escuelas secundarias y en la enseñanza media, y, por tanto, quienes serán responsables de reproducir la historia aprendida a lo largo de su formación universitaria expandiendo dicho conocimiento sobre el pasado. Y de igual manera, las Universidades generan y desarrollan los avances en el conocimiento del pasado, donde los investigadores y académicos producen nuevas formas de aproximarse al pasado, nuevas perspectivas, nuevos interrogantes, nuevas

\footnotetext{
${ }^{6}$ Soto Carmona, "Ni modélica ni fracasada", 119-200.

${ }^{7}$ Keith Jenkins, Repensar la historia (Madrid: Siglo XXI, 2009), 9-10.
} 
tendencias teóricas que, finalmente, redundan en novedades en el conocimiento del pasado, en espacios de luz sobre la oscura realidad pasada.

Dentro de la misma institución universitaria, se pueden ver entremezcladas varias funciones tradicionales de la historia. Por un lado, está presente la función teórica de la historia que busca explicar y comprender el pasado, sin limitarse a la mera acumulación de datos y acontecimientos $^{8}$. Esta función sería desarrollada por investigadores que trabajan para generar nuevas aportaciones al conocimiento, para profundizar en la comprensión del pasado y en su amplia explicación. Pero, por otro lado, dentro de esta misma institución, se desarrolla la función social, aquella que "centra el interés de la historia en el conocimiento y comprensión del presente. [Y] pretende establecer una cierta organización del pasado que dé respuestas a las necesidades del presente" 9 .

La capacidad de formar profesionales que entiendan el pasado y expliquen el presente, personifica y encarna claramente dicha función de la historia. Esos profesionales formados en las aulas universitarias transmitirán el conocimiento del pasado, dando respuesta a los interrogantes de por qué y cómo hemos llegado a vivir en este presente. Esta funcionalidad social de la historia, ejercida en las universidades, así como en colegios, institutos y liceos, está estrechamente relacionada con el acontecimiento fundador de los sistemas políticos que rigen actualmente nuestra convivencia. La necesidad de reproducir una historia que genere aceptación del sistema establecido, así como la promoción de un pensamiento favorable al mantenimiento de este, coloca a la historia como gran protagonista de esta tarea, de ahí su función social. Así pues, la responsabilidad social, pero también política, que recae sobre esos profesionales es crucial: generarán ciudadanos para que habiten, entiendan y continúen el sistema político actual, la democracia conseguida, a través de la reproducción de la historia de las transiciones.

Planteamos, de esta forma, la necesidad de analizar el funcionamiento de las Universidades y comprobar si es efectiva la dualidad de funcionalidades de la historia -social y teórica-, o lo que es lo mismo, si los avances de la academia finalmente llegan a la sociedad, si esos avances se enseñan en las aulas universitarias y el conocimiento se transmite a los niveles medios de educación. Si efectivamente, los nuevos logros conseguidos en el conocimiento sobre los procesos transicionales, así como el engrosamiento y evolución de la historiografía de

\footnotetext{
${ }^{8}$ Primitivo Sánchez Delgado, "El valor de la historia y los valores en la enseñanza de la historia", Revista complutense de educación 2, n. 2 (1991): 313.

${ }^{9}$ Sánchez Delgado, " El valor de la historia", 312.
} 
estos procesos fundadores, se imparte efectivamente en las aulas universitarias. El peligro de que así no ocurra podría acarrear que el conocimiento intelectual y académico quedase recluido en el círculo cerrado, casi elitista, de los pocos que llegan a especializarse y a profundizar en el conocimiento de la historia como disciplina. Y lo que podría ser peor, se formaría a científicos que elaborarían teorías sobre el orden social, explicaciones y perspectivas innovadoras, pero sin los mecanismos para cambiarlo ${ }^{10}$, sin la capacidad de retrasmitirlo a la sociedad y generar voces críticas y renovadoras que generen transformaciones profundas.

Estas inquietudes nos llevan a preguntarnos acerca de la trasmisión del conocimiento sobre los procesos transicionales que son a todas luces los acontecimientos que dieron origen al nuevo orden democrático actual. La necesidad de entender cómo funciona y cómo se transmite el conocimiento sobre los procesos de inauguración de las democracias capta toda nuestra atención y preocupación, planteando los siguientes interrogantes: ¿Cómo se estudian las transiciones en las Universidades?, ¿se respeta la pluralidad de visiones que existen sobre el proceso?, ¿hay algún discurso más estudiado que otro?, ¿los historiadores y profesores de historia conocen realmente esas diversas visiones?, ¿las estudian en sus formaciones universitarias? Estas cuestiones plantean así la problemática central a la que queremos acercarnos e intentar dar respuesta, colocando como objeto de estudio las aulas universitarias y su funcionamiento, así como las diferentes perspectivas sobre el proceso que en éstas se tratan. El objetivo es analizar las asignaturas que puedan estudiar la historia de las transiciones, que ya se explicará qué problemáticas conlleva — cuáles son susceptibles de impartirla, cómo accedemos a la información sobre la asignatura-, identificar qué bibliografía se utiliza o menciona en dichas aulas y seleccionar aquellas monografías más utilizadas para su enseñanza; intentando corroborar así la existencia de una enseñanza plural o limitada a pocas visiones sobre el proceso en las asignaturas analizadas.

\section{Casos de estudio y comparación}

Antes de continuar con el desarrollo e intento de resolución de la problemática planteada, es necesario puntualizar qué casos exactamente estamos tratando en esta investigación. Las transiciones democráticas han copado gran parte de las últimas décadas del siglo XX, desde el Sur de Europa, hasta América Latina, pasando por las antiguas repúblicas soviéticas y Sudáfrica. Dentro de este amplio mapa de transiciones políticas, existen dos procesos que encarnan la misma tendencia reformista y que por ello, comparten interesantes

\footnotetext{
${ }^{10}$ Sánchez Delgado, " El valor de la historia", 310-311.
} 
elementos estructurales. Incluso antes de la transición, el régimen del General Pinochet en Chile, intentó imitar y simular el régimen franquista español ${ }^{11}$. Ambas dictaduras, se reformarán, es decir, aplicarán a la democracia a través de una reforma política de las antiguas instituciones $^{12}$. A pesar de la diferencia geográfica y cronológica ${ }^{13}$, el contacto entre regímenes autoritarios, el análogo procedimiento de instauración de la democracia y las similitudes en el funcionamiento del sistema político creado, sustentan nuestro alegato para efectuar nuestras preguntas de investigación en estos dos casos de transiciones democráticas. Son casos que son diferentes a simple vista, pero que tienen elementos muy similares, que no iguales -qué sentido tendría estudiar dos cosas que son iguales-.

Una vez explicitados los casos de estudio que van a protagonizar nuestra investigación, nos centramos en nuestro objetivo: desentrañar cómo se enseñan las transiciones democráticas en España y Chile en las Universidades de cada país. Este propósito nos conduce directamente a inspeccionar y a revisar exhaustivamente las páginas web de las universidades seleccionadas. En total se han registrado 70 páginas web de 35 universidades de cada país.

Para la selección de las universidades a analizar se han incluido tanto universidades públicas como privadas. En el caso de Chile se han añadido las universidades que forman parte del CRUCH (Consejo de Rectores de las Universidades Chilenas). Se trata de un organismo de coordinación de la labor universitaria del territorio chileno integrado por los rectores de 27 universidades chilenas. El papel de este organismo ha sido el establecimiento de un sistema de selección y admisión de alumnos universitarios, así como en la redacción e implementación de leyes relacionadas con la educación superior ${ }^{14}$. La lista de Universidades de este organismo ha servido de guía para seleccionar universidades en todas las regiones de Chile, más algunas otras

\footnotetext{
${ }^{11}$ Carlos Huneeus Magde, El régimen de Pinochet (Santiago de Chile: Editorial Sudamérica, 2001).

12 Juan J. Linz, "La transición española en perspectiva comparada", en Historia de la transición (1975-1986), ed. Javier Tusell y Álvaro Soto Carmona (Madrid: Alianza Editorial, 1996), 21-46.; Luis Lorente Toledo, "España y el Cono Sur de América Latina. Transiciones y flujo democrático", en Historia de la transición y consolidación democrática en España (1975-1986) II. Perspectiva internacional. Análisis comparado. Política exterior. Economía, sindicatos y sociedad, ed. Javier Tusell y Álvaro Soto Carmona (Madrid: UNED, UNAM, 1995), 3546; Álvaro Soto Carmona, "Diálogos y encuentros", en Chile y España diálogos y encuentros, de Joaquín Almunia y Genaro Arriagada (Aguilar, 2002); Huneeus Magde, El régimen de Pinochet; Carmen González Martínez y Encarna Nicolás Marín, "Presentación: De la dictadura a la democracia en España y Chile, nuevas perspectivas", Ayer, Procesos de construcción de la democracia en España y Chile., n· 79 (2010): 13-30; Yurena González Ayuso, “Transiciones democráticas: Chile y España en perspectiva comparada, 1976-1990”, en Quintas Jornadas de Jóvenes Investigadores de la Universidad de Alcalá: Humanidades y Ciencias Sociales, ed. Cristina Tejedor Martínez et al. (Alcalá de Henares: Universidad de Alcalá, Servicio de Publicaciones, 2016), 137-46.

${ }^{13}$ La transición española se inicia en la década de los setenta y la chilena en los noventa. Elegimos dar una cronología amplia, en décadas, por la variedad de opciones cronológicas que existen entre la comunidad académica para iniciar y finalizar las transiciones en ambos casos.

14 "Consejo de Rectores de las Universidades Chilenas", accedido 23 de noviembre de 2017, http://www.consejoderectores.cl/historia.
} 
privadas en su mayoría, completando la cifra de Universidades con carreras en Historia o Pedagogía en Historia y Geografía. Esta selección nos proporciona una idea muy completa del sistema universitario chileno, ofreciéndonos información de las universidades más importantes del país, así como su oferta académica y funcionamiento.

En el caso de España, también encontramos una institución que reúne periódicamente a los rectores de las principales Universidades españolas, el CRUE (Conferencia de Rectores de Universidades Españolas). Este organismo tiene como función principal ejercer de interlocutor entre el gobierno central y las distintas universidades adscritas, en este caso 50 públicas y 26 privadas $^{15}$. De esta organización, hemos podido obtener un listado online de un gran número de universidades españolas, con el cual completar y realizar nuestra investigación. No se han utilizado la lista completa del CRUE, se ha optado por la selección geográfica de las universidades, manteniendo una universidad al menos por cada comunidad autónoma, repitiendo aquellas en las que hay más número de universidades, como Madrid, Andalucía o Cataluña. En España la pluralidad de programas y métodos provocada por la descentralización de la educación ${ }^{16}$ nos obliga a tomar las universidades por regiones administrativas e intentar añadir casos de todas las regiones ${ }^{17}$, para tener una representatividad lo más completa posible.

\section{Universidades y carreras}

El primer objetivo en nuestra búsqueda es identificar si se imparten o no carreras de Historia o relacionadas con ella. En este caso es interesante descubrir que, en 10 de las 35 universidades chilenas seleccionadas, sí imparten Licenciatura de Historia, pero en las otras, o no se imparte (9 de 35 universidades), o se imparte Pedagogía en Historia, Geografía y Ciencias Sociales o Pedagogía en Historia, Geografía y Educación Cívica, (16 de 35) (Consultar Anexos). Vemos, por lo tanto, que la historia como disciplina unitaria no está tan extendida como en España, donde las carreras encontradas en su mayoría son Grado en Historia, Grado en Historia y Geografía, o en su defecto Grado en Filosofía, Política y Economía en la Universidad de Deusto (Consultar Anexos). Obviamente el funcionamiento universitario es distinto, apareciendo aquí una de las primeras diferencias entre los dos casos

\footnotetext{
15 “CRUE - Inicio", accedido 15 de febrero de 2018, http://www.crue.org/SitePages/Inicio.aspx.

16 Fernando Vallespín, “Qué le pasa a la universidad española?”, EL PAÍS, 20 de agosto de 2017, https://elpais.com/elpais/2017/08/19/opinion/1503161501_791914.html.

${ }^{17}$ La lista de universidades consultadas y las páginas web correspondientes se añade en los anexos. Pero tanto la página web del CRUE como la del CRUCH ofrecen un link a cada una de las universidades que hemos trabajado en esta investigación.
} 
En Chile, con esta primera observación, podemos detectar que estas carreras están enfocadas a la educación, lo cual nos indica que hay una separación interesante entre Historia y Pedagogía: para ser profesor de historia no se exige necesariamente ser historiador -con todo lo que ello conlleva-. Por el contrario, en España, no se da esa diferenciación tan fuerte en un inicio, ya que independientemente de la profesión que después se elija -pedagogía o investigación histórica-, ambas parten del grado en Historia. Esta diferencia inicial nos hace pensar que el sistema universitario chileno está más destinado o enfocado en la profesionalización de sus estudiantes, generando ofertas académicas adaptadas a este propósito y con el objetivo de que puedan insertarse rápidamente en el mundo laboral, en este caso a liceos como profesores de Historia, Geografía o Educación Cívica. Este enfoque puede verse más dislocado en España donde la ligazón con la Pedagogía, función básica de la Historia como hemos mencionado antes (generar ciudadanos que comprendan el pasado y acepten el presente), está fuera de la formación básica de los historiadores españoles; quienes elegirán en el futuro si acercarse a la rama pedagógica o continuar la formación investigadora, opción que tienen todos al haberse formado como historiadores, a pesar de no estar tan enfocados al mercado laboral de docencia, como veíamos en el caso chileno. Cada sistema universitario, como vemos, tiene sus carencias y excesos, cada uno favorece ciertos elementos de la formación de profesionales y perjudica otros.

\section{¿Contemporáneo o actual?}

Además de identificar una selección de universidades en cada caso con carreras o estudios en Historia, se procede a seleccionar cuáles son las asignaturas susceptibles de incluir en su contenido los procesos históricos que nos interesan en este trabajo. En esta delimitación, donde pretendemos identificar en qué asignatura se engloban las transiciones democráticas, se encuentra uno de los debates historiográficos más interesantes y trascendentales de la teoría histórica: ¿cuándo acaba una época histórica y empieza la siguiente?, ¿con qué argumentos englobamos un acontecimiento histórico dentro de una determinada época?, ¿las transiciones democráticas son historia contemporánea o historia actual?, ¿dónde situamos un acontecimiento tan trascendental?

El inicio de la Historia Contemporánea parece estar claro y hay cierto consenso entre la comunidad académica e historiográfica: se situaría a partir de la Revolución Francesa y el desarrollo del liberalismo y del Estado-nación. El problema y el debate viene cuando esta historia o esta época quiere cerrarse. ¿Cuándo deja de ser Historia Contemporánea?, ¿qué acontecimiento supone el fin de la época contemporánea? Si además recordamos la paradójica 
frase de Benedetto Croce: "toda historia es historia contemporánea"18 el debate se pone mucho más interesante. ¿Dónde integramos los acontecimientos tan recientes como las transiciones democráticas que poco tienen que ver con los inicios del siglo XIX?, ¿pertenecen al mismo tiempo histórico?, ¿qué entendemos por tiempo histórico?

Ante la insidiosa necesidad de darle un cierre a la historia contemporánea y de integrar nuevos acontecimientos, se han perfilado las características y limitaciones para dar cabida a un nuevo periodo histórico, el cual debe poseer elementos estructurales distintos y generar un mundo cualitativamente diferente al anterior. De esta forma, Aróstegui asegura que:

Todo tiempo histórico definible surge de una matriz [...] de un acontecimiento monstruo del que nacen los caracteres esenciales de toda una época, o cabe decir también que ese tiempo parte de un momento axial, un punto sobre el que se construye un cierto modelo de inteligibilidad ${ }^{19}$.

Muchos autores consideran que la II Guerra Mundial daría lugar a un nuevo mundo, a nuevas estructuras y actores políticos, a otras preocupaciones y a generar nuevas formas de entender la realidad a partir de una nueva matriz ${ }^{20}$. El mundo "entraría" en una nueva contemporaneidad. Esta nueva fase iniciada a partir de 1945 y su estudio ha adquirido el nombre de Historia Actual, Historia del Tiempo Presente o Historia del Presente, sobre todo a partir de la creación del Instituto de Historia del Tiempo Presente en París en $1979^{21}$. A partir de los estudios generados en torno a esta institución se fue afianzando la separación entre épocas y la designación de un nuevo periodo histórico a partir de la II Guerra Mundial. La nueva denominación nos dejaría con la paradoja de continuar llamando a la historia del XIX y principios del XX contemporánea, siendo esta la de hace más de dos siglos, dejando de ser literalmente contemporánea. O no. Tomaremos la definición de Navajas Zubeldía para entender mejor este punto:

\footnotetext{
${ }^{18}$ Carlos Navajas Zubeldía, "El regreso de la 'verdadera' historia contemporánea", Revista de historia actual, $\mathrm{n}^{\circ} 1$ (2003): 143 .

${ }^{19}$ Julio Aróstegui Sánchez, La historia vivida: sobre la historia del presente (Madrid: Alianza Editorial, 2004), 209.

${ }^{20}$ Julio Aróstegui Sánchez, "El presente como historia (La idea de un análisis histórico de nuestro tiempo)", en Actas del Primer Simposio de Historia Actual de La Rioja : Logroño, 14-18 de octubre de 1996, 1996, ISBN 8489362-14-9, 17-44 (Actas del Primer Simposio de Historia Actual de La Rioja : Logroño, 14-18 de octubre de 1996, Instituto Interuniversitario de Desarrollo Social y Paz, 1996), 17-44; Aróstegui Sánchez, La historia vivida; Josefina Cuesta Bustillo, "La historia del tiempo presente: estado de la cuestión", Studia historica. Historia contemporánea, n 1 (1983): 227-41; Navajas Zubeldía, "El regreso de la "verdadera" historia contemporánea".

${ }^{21}$ Cuesta Bustillo, "La historia del tiempo presente", 229-230.
} 
Nuestra tesis es la de que la Historia Actual es la "verdadera" historia contemporánea y que el periodo comprendido entre 1800, aproximadamente, y el principio de la Primera Guerra Mundial forma parte de otra edad: la que podríamos denominar edad contemporánea temprana ${ }^{22}$.

A pesar de la facilidad para adoptar nuevas denominaciones en nuestra disciplina, esta periodización pareciera que consigue apaciguar las dudas sobre las delimitaciones entre Historia Contemporánea y Actual: Historia Actual para el periodo posterior a 1945, Historia Contemporánea para el periodo anterior. Aun así, hay que tener presente que este debate historiográfico tiene mucho más interés si lo bajamos al nivel de nuestros casos de estudio.

En el caso español, está claro a qué historiador debemos recurrir para entender qué es la historia actual o historia del tiempo presente. El profesor Julio Aróstegui es el icono de esta disciplina y nos ofrece una reflexión directamente relacionada con los procesos políticos que nos interesan. Y es que, para este historiador del presente, en España se había impedido o al menos, atrasado la irrupción y el interés por la Historia del Tiempo Presente por la presencia y larga duración del franquismo. Es más, aseguraba que la matriz del tiempo presente durante décadas había sido la Guerra Civil; el acontecimiento monstruo que había generado un nuevo paradigma y una nueva realidad totalmente distinta a la anterior ${ }^{23}$. Añadiendo como dato interesante para este estudio que la matriz del tiempo presente actualmente en España es precisamente la transición a la democracia. El proceso que explicaría las estructuras y al que debemos recurrir para entender el presente sería precisamente la transición ${ }^{24}$. El paradigma democrático creado con este proceso nos ofrece las claves del presente. De esta manera, en el caso de España entraría más fácilmente a englobarse dentro de la Historia Actual, más que de la Historia Contemporánea, como nos sugiere Aróstegui.

Para el caso chileno debemos recurrir al historiador Ángel Soto Gamboa, quien se acerca mucho a los postulados de Aróstegui y nos facilita la comprensión de la problemática que planteamos. El autor también advierte elementos similares con el proceso español y asegura que no es hasta la finalización de la transición cuando se inicia la discusión académica sobre la "factibilidad del estudio de la historia del presente" 25 . En la obra de este autor podemos encontrar las reticencias de sus colegas historiadores ante la investigación sobre procesos

\footnotetext{
${ }^{22}$ Navajas Zubeldía, "El regreso de la "verdadera” historia contemporánea”, 149.

${ }^{23}$ Aróstegui Sánchez, La historia vivida, 49.

${ }^{24}$ Aróstegui Sánchez, La historia vivida, 49.

25 Ángel Soto Gamboa, El presente es historia: reflexiones de teoría y método (Santiago de Chile: Eds. Centro de Estudios Bicentenario : CIMAS, Facultad de Comunicación Universidad de Los Andes, 2006), 20.
} 
recientes en el ámbito historiográfico chileno. La comunidad de historiadores se ve frenada a investigar y a trabajar procesos recientes como la transición, alegando argumentos como: la cercanía, la falta de imparcialidad, la falta de fuentes, el uso político de la historia, etc. ${ }^{26}$. Soto asegura que: "la historia del presente fue expulsada del quehacer historiográfico por el positivismo, que vincula la historia con el pasado, un pasado desvinculado epistemológicamente del presente" 27 . Las reticencias para aceptar la Historia Actual como nueva disciplina histórica, como asegura Soto Gamboa, y el poco tratamiento que ha tenido el proceso de transición por los historiadores chilenos -la gran mayoría de investigadores que se acercan a la transición chilena son politólogos o sociólogos-, nos ofrece un importante argumento para asegurar que el proceso transicional se englobaría dentro de este periodo de Historia Actual o Historia del Tiempo Presente, a pesar del poco o, al menos, no tan profundo trato dado por la academia chilena.

Un argumento más para entender las reticencias de la historiografía chilena a entrar en temas tan recientes como la transición, o por ejemplo los problemas de memoria heredados de la dictadura, nos sirve la aportación del historiador chileno Julio Pinto, quien, en su revisión de la historiografía académica, hace especial hincapié en las reticencias, no sólo de la academia, sino también de la sociedad para comenzar a cuestionarse su pasado reciente. Para este autor, no es hasta 1997, con la publicación de la primera crítica a la transición Chile Anatomía de un mito $^{28}$ cuando se extiende el espíritu crítico y comienzan las investigaciones y publicaciones sobre la memoria y las violaciones a los derechos humanos: “[...] el severo diagnóstico de Moulián sobre el carácter básicamente continuista de los gobiernos de recuperación democrática indujo a decenas de miles de chilenas y chilenos a repensar las tres últimas décadas, y a tomar conciencia de lo mucho que aún quedaba por resolver" ${ }^{29}$. Esta breve cita nos hace comprender las dificultades que suponía cuestionarse el pasado en Chile en según qué momentos, y a la vez, a identificar la especial y estrecha relación entre interés público y social amplio, con intereses académicos e historiográficos, los cuales, a pesar de su situación de vanguardia, no es hasta que la sociedad está más receptiva cuando empieza a adoptarlos y generar nuevas tendencias.

\footnotetext{
${ }^{26}$ Soto Gamboa, El presente es historia; Ángel Soto Gamboa, “¿Qué es la historia del presente? Un intento de conceptualización”, Información pública, n· 2 (2003): 534-38.

${ }^{27}$ Soto Gamboa, El presente es historia, 38.

${ }_{28}^{2}$ Tomás Moulián, Chile actual. Anatomía de un mito (Santiago de Chile: LOM Ediciones, 1997).

${ }^{29}$ Julio Pinto Vallejos, La historiografía chilena durante el siglo XX. Cien años de propuestas y combates (Valparaíso: América en Movimiento Editorial, 2016), 107.
} 
La lentitud y la postergación de la entrada de la historia como ciencia social para explicar los procesos de transición e introducir este proceso político y social dentro de la temática de Historia es una característica que vemos de forma similar en los dos casos seleccionados. Otro elemento más a señalar de la peculiar relación que efectúan estos dos casos tan distintos a simple vista.

Una vez expuestas las diferencias historiográficas entre Historia Actual e Historia Contemporánea y teniendo presentes cuáles son las diferencias fundamentales entre uno y otro caso (en España la acepción de Historia Actual está mucho más extendida que en Chile, donde hay muchas más reticencias a su utilización y extensión), así como sus semejanzas se ha procedido a identificar las asignaturas susceptibles de estudiar el proceso de transición dentro de los programas de las carreras de Historia y Pedagogía de las universidades analizadas.

El primer dato que podemos arrojar es que no en todas las universidades se imparten asignaturas de Historia de España Actual o Historia de Chile Actual ${ }^{30}$. Según lo que hemos podido detectar, en la gran mayoría de carreras la asignatura más extendida para estudiar el final del siglo XX es Historia Contemporánea, o cualquiera de sus variantes (Historia Contemporánea I y II, Historia Contemporánea del siglo XIX y XX). La problemática que esto genera, más allá del interesante debate historiográfico que hemos mencionado anteriormente, es claramente pragmática. El docente que debe impartir dos siglos de historia en la asignatura de Historia Contemporánea es muy probable que se vea apremiado por la gran carga de materia y contenido y el final del siglo XX, es decir, el periodo de las transiciones, el periodo que explica el presente, sea tratado mucho más brevemente, o si quiera tratado. La gran diferencia radica, por tanto, en si ese docente que imparte Historia Contemporánea sabe que dentro del programa de la carrera hay otras asignaturas que se centran de lleno en el final del siglo XX como puede ser Historia Actual. En este caso, el periodo no quedará en el tintero y será estudiado con mucha más profundidad sin compartir tiempo de docencia con otros hitos históricos trascendentales como los que pueden protagonizar asignaturas tan generales como Historia Contemporánea.

Pero ¿cuáles son los datos? Pues bien, los datos de las universidades chilenas nos informan que solamente en cuatro de ellas existen asignaturas de Historia Actual, el resto no tienen este tipo de asignatura, englobándose en Historia Contemporánea el estudio del proceso. El $89 \%$ de las Universidades chilenas no tienen asignaturas que abarquen la Historia Actual

\footnotetext{
${ }^{30}$ Se utilizará la cursiva para señalar el nombre de las asignaturas y diferenciarlas de la disciplina historiográfica. Lo mismo sucede con Historia Contemporánea (disciplina) e Historia Contemporánea (asignatura).
} 
(Consultar Anexos). En cambio, para el caso de España, como veíamos en el campo historiográfico, la asignatura de Historia Actual está mucho más extendida, siendo un $57 \%$ las universidades que imparten este tipo de asignaturas (Consultar Anexos).

No podemos saber exactamente con estos datos cómo se imparten las clases de cada asignatura, no hemos estado presentes en estas aulas, pero consideramos que la extensión de programas universitarios que contemplen la problemática de la Historia Actual y la impartan como una asignatura más, presentarán una sensibilidad mayor a la hora de tratar los procesos de transiciones democráticas. Por lo tanto, podemos suponer que en aquellas universidades donde dicha asignatura se imparta el nivel de profundización y estudio al proceso histórico que nos ocupa será mucho más alto que en programas en los que esta asignatura no aparezca.

\section{¿Asignatura obligatoria u optativa?}

Otro elemento esencial para entender la magnitud de la extensión del conocimiento en estos procesos es identificar el carácter obligatorio u optativo que tengan las asignaturas dedicadas al proceso de transición, sobre todo para el caso español en el que sí existen este tipo de asignaturas. Sólo en algunos casos se ha dado que la asignatura de Historia Actual sea impartida como optativa, por lo que podemos entender que en la mayoría de las carreras universitarias el periodo va a estudiarse de forma exclusiva con la implementación de esta asignatura.

Es más, en varias universidades, encontramos asignaturas mucho más específicas que Historia Actual para estudiar el periodo de las transiciones, pero estas sí de carácter optativo en todos los casos. Es el caso de la asignatura de Dictadura y Democracia en el siglo XX español, impartida en la Universidad Autónoma de Madrid; La democracia en el Mundo Occidental: Procesos de Construcción, en la Universidad de Almería; o España Contemporánea entre dictaduras y democracia impartida en la Universidad de Castilla-La Mancha. Como puede comprobarse con el nombre de las asignaturas y examinando los programas completos en aquellos casos en los que las páginas web los incluyen, éstas se centran en el periodo de transición para el caso de España, pudiendo afirmar que son las asignaturas más variadas y específicas sobre el proceso. Recuérdese que se trata de asignaturas optativas, y que, por lo tanto, no podemos presuponer la generalización de este tipo de enseñanza del proceso de transición. Al ser optativa no todos los estudiantes la impartirán y algunos no conocerán todos los elementos característicos de la formación del sistema político en el que viven. 
Pero qué sucede en el caso chileno. Pues bien, en primer lugar, las mallas curriculares no contemplan asignaturas optativas en las carreras universitarias, todas las asignaturas ofertadas son de carácter obligatorio. Por lo tanto, entendemos que sólo nos queda confiar en la extensión de las asignaturas referentes a Historia Actual o Reciente de Chile. En este caso, pueden contarse fácilmente: en la Universidad Metropolitana de Ciencias de la Educación: Historia de Chile IV: Segunda Mitad del Siglo XX; Universidad Andrés Bello: Chile Actual; Universidad Austral de Chile: Chile Reciente; Universidad de los Andes: Historia de Chile Reciente; Universidad Católica de Temuco: América y Chile en los siglos XX y XXI (Consultar Anexos). En todos estos casos se trata siempre de asignaturas obligatorias y está claro que en la denominación abarca el periodo de la transición a la democracia, y que, muy probablemente, sea en estas asignaturas donde encontremos un mayor grado de especialización en la materia, como venimos sosteniendo hasta ahora.

La gran diferencia que estamos identificando con el caso español se ve confirmada de nuevo al identificar y enumerar fácilmente aquellas mallas curriculares que imparten asignaturas de Historia Actual en Chile, siendo la tónica generalizada su ausencia en la gran mayoría de los casos. Afirmando de nuevo que, esa diferenciación historiográfica que mencionaba Soto Gamboa en el ámbito chileno reticente a estudiar la Historia Actual se ve reflejada en los programas universitarios y en las materias que se imparten, siendo esta asignatura, como veíamos, muy poco extendida en Chile. Sin mencionar, por supuesto, la ausencia de asignaturas dedicadas exclusivamente al estudio de la transición, aunque fuera de forma optativa como en España.

En cambio, es interesante remarcar un factor interesante en el caso chileno. Dentro de las carreras de Pedagogía analizadas existe una tipología que incluye Historia y Geografía, pero también Educación cívica. Esta formación es bien interesante porque responde a la necesidad de formar un grupo específico de profesorado para la asignatura creada recientemente destinada a todos los niveles de enseñanza en Chile ${ }^{31}$. Su objetivo principal es explicar y generar un ambiente cívico, ciudadano y democrático en las aulas de los alumnos más jóvenes, donde se enseñen las formalidades de cómo ser un buen ciudadano chileno, el nivel de participación política y entender el funcionamiento del sistema en el que habitan. Vemos como a pesar de tener una falla en la formación de profesorado en cuanto a Historia Actual o al tema de la

\footnotetext{
${ }^{31}$ El Mercurio S.A.P, "Bachelet promulga ley que introduce la formación cívica en todos los colegios del país | Emol.com", Emol, 28 de marzo de 2016, http://www.emol.com/noticias/Nacional/2016/03/28/795187/Bacheletpromulga-ley-que-incluye-la-formacion-ciudadana-en-los-colegios.html.
} 
transición, la educación en Chile percibe actualmente impartir una asignatura que, aunque no desde una perspectiva específicamente histórica, sí genere la formación y el conocimiento sobre el sistema vigente en el Chile actual.

\section{¿Grado o magíster?}

Es a nivel magíster donde tenemos que acudir para identificar un grado de especialización más profundo en la problemática de la transición. Así pues, en Chile encontramos asignaturas tales como Los nudos históricos de la transición chilena a la democracia. Actores y coyunturas políticas (1983-1998) en el Magíster de Historia de la Universidad de Santiago de Chile, con un nivel de profundización alto, ya que en dicha asignatura la temática central es la transición chilena. De hecho, es dirigida por el especialista en la transición chilena Pablo Rubio Apiolaza, importante investigador chileno especializado en el estudio de la transición.

Lo mismo sucede con el Máster interuniversitario de Historia Contemporánea impartido por varias Universidades españolas: Universidad Autónoma de Madrid; Universidad Complutense de Madrid; Universidad Autónoma de Barcelona; Universidad de Santiago de Compostela; Universidad de Valencia; Universidad de Cantabria; Universidad del País Vasco/Euskal Herriko Unibersitatea; Universidad de Zaragoza; Universidad Internacional Menéndez Pelayo. La pluralidad de Universidades y el alto nivel académico alcanzado con este máster nos sirve de guía y ejemplo para el caso español, donde no encontramos un máster de tan alto nivel académico ${ }^{32}$. En este máster el nivel de especialización, tanto en la transición española como en la chilena es muy profundo. Encontramos así asignaturas como El Estado y el espacio público. Transiciones a la democracia en el siglo XX impartida en la Universidad Autónoma de Barcelona por Pere Ysás o Autoritarismo y Democracia impartida por Álvaro Soto Carmona en la Universidad Autónoma de Madrid. Asignaturas ambas que incluyen estudios no sólo de la transición española sino de otros casos como el chileno. La dirección de las asignaturas, en efecto, corresponde a dos importantes investigadores expertos en el tema de las transiciones, suponiendo de esta forma, que el grado de especialización y profundización alcanzado en las aulas de estas asignaturas es exhaustivo y cubre las especificaciones del tratamiento de un tema tan crucial como el de las transiciones.

La importancia de introducir en nuestro análisis el nivel magíster, aunque se trate de pocos casos, pero significativos, es interesante porque nos demuestra el nivel de especialización

\footnotetext{
${ }^{32}$ Fuente: https://www.ucm.es/hcontemporanea/posgrado Consultado: 28/10/2017.
} 
que ha adquirido la formación en este tema y el nivel académico al que llega, así como el contacto y dualidad entre función teórica y función social de la historia. Las innovaciones del conocimiento no llegan al nivel de grado -aunque como vemos, sí a nivel de postgrado-, y se da una formación precaria en el conocimiento general de este tema, teniendo en cuenta la existencia de una gran cantidad de debates y novedades historiográficas que han suscitado los procesos.

\section{Guías docentes}

Otro dato que hemos tenido en cuenta para tratar la problemática del estudio de las transiciones en las Universidades e intentar adentrarnos más profundamente en el funcionamiento de las asignaturas seleccionadas, ha sido la consulta y el almacenamiento de las guías docentes de dichas asignaturas. La importancia del análisis de las guías docentes es crucial si se quiere entender la profundidad y pluralidad con la que se imparten los procesos que nos interesan. Una guía docente en la que la gran parte de la bibliografía recomendada esté centrada en las transiciones nos indica que la asignatura se enfoca en ese periodo histórico, nos muestra la preocupación del docente en presentar las problemáticas fundamentales del proceso. Y si además cuenta con bibliografía especializada y variada, podemos entender también que hay una intención por parte del docente de presentar las diferentes y plurales perspectivas que existen sobre el proceso. De esta forma, al identificar bibliografía general, como manuales extensos sobre el siglo XX y sin bibliografía especializada, nos indica que este periodo es tratado en la asignatura de manera secundaria y no es una de las problemáticas fundamentales tratadas a lo largo de la asignatura. Esta importante información y diferenciación sólo es revelada con la consulta de la bibliografía que existe en las guías docentes, no sólo de forma cuantitativa, sino también cualitativa. Además de cuanta bibliografía se utiliza, la pregunta clave es también cuál.

Nuestro trabajo se ha basado, por lo tanto, en la recopilación, en ocasiones fallida, de las guías docentes de las asignaturas tanto de Historia Contemporánea de Chile y España, como de Historia Actual de los dos casos, así como de las asignaturas más especializadas. La consulta de su guía docente nos ha aportado, en los casos que ha sido encontrada, la bibliografía utilizada y recomendada en la clase para ayudar al alumno a su comprensión. Aun así, el trabajo con las guías docentes plantea varios problemas que deben ser tenidos en cuenta.

El primero obstáculo que conlleva almacenar y analizar la bibliografía de las guías docentes de ciertas asignaturas es que no siempre, en el ritmo de una clase, la guía docente se 
sigue al pie de la letra, lo mismo que la planificación. Es una guía que proporciona lo que el profesor prepara para estudiar e impartir en clase, pero debemos tener en cuenta que no siempre se trabajará toda la información que ésta arroje. Aun así, creemos que podemos sustentar nuestra información en estas guías, ya que finalmente, al ser destinadas a guiar las clases, así como a los alumnos, siempre será la primera referencia que los estudiantes tendrán para profundizar en el tema de las transiciones. Por lo tanto, el hecho de que se recomiende o cite cierta bibliografía, seleccionada previamente por el docente e investigador, nos va a aportar la información que buscamos, aunque siempre teniendo presente que no necesariamente va a utilizarse por completo en todos los casos.

Otro problema con las guías docentes que hemos detectado es que no siempre están disponibles en las páginas web de las universidades. Esto supone que no se han podido analizar todas las asignaturas de todas las carreras consultadas. Además de la posible falta de organización y que la alternancia de docentes en las mismas asignaturas haga complicada la actualización de esa información, en muchas ocasiones el acceso a las guías docentes es problemático. Parte de la información recopilada fue facilitada por contacto directo con los docentes encargados de la asignatura, lo cual posibilitó el acceso directo sólo a algunas guías. Pero debe tenerse en cuenta que lamentablemente no se ha podido acceder a la totalidad de las universidades y los resultados aquí arrojados van a ser sólo los referidos a la información que ha podido ser recopilada hasta ahora. Es interesante mencionar que aquí resalta otra gran diferenciación entre los casos estudiados. En las universidades españolas se han encontrado las guías docentes con más facilidad y están a disposición de todo el público que accede a la página web de la universidad, pero en cambio en las universidades chilenas esta información ha sido más costosa de encontrar en la mayoría de las páginas webs, y en este caso es donde más se ha recurrido a la petición personal de la guía docente. Nos guiaremos en nuestras conclusiones de los datos arrojados por la información recopilada hasta ahora.

Hechas las puntualizaciones sobre las dificultades que presenta el trabajo con guías docentes, y continuando con la dualidad de asignaturas Historia Actual-Historia Contemporánea, el primer dato interesante es que la bibliografía es mucho más extensa, e incluso específica, en las asignaturas de Historia Actual comparadas con las de Contemporánea: el número de bibliografía aportada en la guía docente referente a las transiciones es mucho más alta en la primera (Consultar Anexos). Queda así confirmada la idea que mencionábamos antes a la hora de valorar la proliferación de la disciplina de Historia Actual en los programas universitarios. Estas asignaturas al no tener que compartir materia con 
periodos históricos cruciales como la primera mitad del siglo XX o el siglo XIX, el docente tiene más tiempo para tratar las problemáticas del final del siglo XX, que en ambos casos se centran en las dictaduras y en los procesos de transición. Esta diferencia cualitativa que venimos sosteniendo en este trabajo se ve apuntalada también al consultar las guías docentes en las cuales la variedad y la cantidad de bibliografía dedicada a los procesos de transición es mucho más visible que en asignaturas de Historia Contemporánea, donde la bibliografía recomendada es mucho más general, con manuales y poca bibliografía especializada.

Lo mismo sucede con las asignaturas optativas en el caso español. Como habíamos identificado, esas asignaturas centradas en el proceso de transición ofrecían una importante variedad bibliográfica, así como una especialización muy alta. Las guías docentes corroboran por tanto esta hipótesis. Así sucede también con los másteres universitarios consultados. Tanto en el caso chileno como en el español, la especialización, diversificación y pluralidad son la tónica constante, además de contar con investigadores especialistas en el tema para ambos casos. El acceso a las guías docentes corrobora la idea de exclusividad en el tema, aportando una variada y rica bibliografía, con monografías especializadas, analizando y tratando varias perspectivas de la transición. Elementos todos ellos claves para generar un profundo conocimiento crítico sobre los procesos de transición.

\section{¿Qué historias se enseñan?}

Además de la cantidad de bibliografía, para nuestros objetivos, es necesario analizar y tener en cuenta la calidad de esa bibliografía, el contenido. Así pues, como venimos sosteniendo, los procesos de transición han generado gran número de bibliografía y literatura especializada, desde distintas y variadas perspectivas. Nuestra pregunta inicial se basaba en intentar identificar cuáles eran las visiones más extendidas en las aulas universitarias, así como las monografías y la literatura más recurrente en estos espacios para tratar las transiciones, intentado identificar que visiones y desde que perspectivas era presentada esta problemática. Así pues, el almacenamiento y análisis de las guías docentes nos ha permitido identificar las visiones sobre la transición más extendidas.

En el caso español, los datos nos advierten de que hay varios autores que se repiten en casi todas las asignaturas consultadas. De las universidades revisadas y entre las asignaturas que se consiguieron las guías docentes, en 10 de ellas se utiliza, menciona o se hace referencia a la Transición y cambio en España 1975-199633. Esta sería la obra más utilizada en las aulas

\footnotetext{
${ }^{33}$ Álvaro Soto Carmona, Transición y cambio en España, 1975-1996 (Madrid: Alianza Editorial, 2005).
} 
en las que se estudia la transición española. Le sigue Dictadura y monarquía en España. De 1939 hasta la actualidad ${ }^{34}$; La transición española a la democracia ${ }^{35}$; El mito de la transición: la crisis del franquismo y los orígenes de la democracia (1973-1977) ${ }^{36}$; y Dictadura franquista y democracia, 1939-2004 ${ }^{37}$, utilizadas todas ellas en 4 de todas las asignaturas analizadas (Consultar Anexos). Este sería el elenco de monografías especializadas para analizar la transición por excelencia en España. Estos datos son muy interesantes porque nos arrojan una información crucial sobre la extensión del conocimiento del proceso. Se trata de obras trascendentales en la historiografía española, ya sea por su rigor y aportación, como por la crítica que arrojan. Se trata de visiones tradicionales, como son la reiteración de Tusell y Soto Carmona, pero, curiosamente comparten protagonismo con obras y opiniones tan controvertidas como las de Gallego y Muniesa, autores muy críticos con la transición. Estos datos, aunque esperanzadores al hacer pensar que se extienden también las visiones críticas y la variación en el discurso, ayudan a constatar una recurrente asiduidad en la utilización de un mismo manual general para el estudio de la transición española.

Para el caso chileno, también existe una obra monográfica que en comparación a las demás es la más utilizada con diferencia. Se trata de El régimen de Pinochet ${ }^{38}$ el cual es utilizado en 7 de todas las asignaturas consultadas. A continuación, le siguen la obra ya mencionada Chile actual. Anatomía de un mito ${ }^{39}$; el manual de Historia del siglo XX chileno: balance paradojal ${ }^{40}$ y la compilación El modelo chileno. Democracia y desarrollo en los noventa $^{41}$ con presencia en 4 de las asignaturas identificadas. Les seguiría con tres: El difícil camino a la democracia en Chile ${ }^{42}$; El Chile perplejo. Del avanzar sin transar al transar sin

\footnotetext{
${ }^{34}$ Bernat Muniesa, Dictadura y transición. La España lampedusiana. II La monarquía parlamentaria (Barcelona: Universitat de Barcelona, 2005).

${ }^{35}$ Javier Tusell Gómez, La transición española a la democracia (Madrid: Historia 16, 1997).

${ }^{36}$ Ferrán Gallego, El mito de la transición. La crisis del franquismo y los orígenes de la democracia (1973-1977) (Barcelona: Crítica, 2008).

${ }^{37}$ Javier Tusell Gómez, Dictadura franquista y democracia, 1939-2004 (Barcelona: Crítica, 2005).

${ }^{38}$ Huneeus Magde, El régimen de Pinochet.

${ }^{39}$ Moulián, Chile actual. Anatomía de un mito.

${ }^{40}$ Sofía Correa Sutil et al., Historia del siglo XX chileno: balance paradojal (Santiago de Chile: Sudamericana, 2001).

${ }^{41}$ Paul W. Drake e Iván Jaksic, eds., El modelo chileno: democracia y desarrollo en los noventas, Colección Sin Norte (Santiago: LOM Ediciones, 1999).

42 Paul W. Drake e Iván Jaksic, El difícil camino a la democracia en Chile, 1982-1990 (Santiago de Chile: FLACSO, 1993).
} 
parar $^{43}$; Historia oculta de la transición. Memoria de una época ${ }^{44}$ y El espejismo de la reconciliación política 1990-2002 ${ }^{45}$.

La utilización de estas monografías nos indica varias cosas. En primer lugar, el uso de la obra de Huneeus es muy significativo ya que es un recorrido profundo por todo el régimen autoritario precedente a la transición, conformando un relato de la transición directamente relacionado con el régimen autoritario, explicando sus características, y aportando una visión integral e histórica del pasado reciente. Que sea utilizado para entender la transición, nos indica la intención de presentar el proceso de una forma global, haciendo referencia a los interesantes elementos heredados del sistema autoritario anterior. Podemos suponer de la utilización de este manual que la transición chilena se considera un acontecimiento histórico con profundas y complejas causas, que debe ser mirado en perspectiva histórica y sin olvidar sus precedentes inmediatos, como en este caso nos lo presenta Huneeus.

Por otro lado, como se mencionaba anteriormente, sólo algunos de estos autores son historiadores como Jocely-Holt o Correa, el resto de los autores son politólogos o sociólogos. Así sucede con la obra de Moulián, que como ya hemos dicho, tuvo una enorme repercusión tanto historiográfica como mediática, convirtiéndose en la obra de referencia para analizar la transición chilena. Por otra parte, el resto de las monografías utilizadas, giran sus estudios en torno al problema de la memoria, elemento central en la historiografía chilena de finales del siglo XX y principios del XXI como se mencionaba anteriormente ${ }^{46}$.

\section{Conclusiones}

Tras los datos expuestos y analizadas las repercusiones que pueden tener los diferentes mecanismos de los dos sistemas universitarios, así como la diferente tradición historiográfica, podemos llegar a tres conclusiones fundamentales.

En primer lugar, la gran diferencia entre ambos casos es la importante extensión que encontramos en España de la Historia Actual, tanto a nivel historiográfico como a nivel universitario. La disciplina como ámbito de investigación y estudio está bastante institucionalizada para adentrarse y profundizar en el análisis de la transición. Recuérdese la

\footnotetext{
${ }^{43}$ Alfredo Jocelyn-Holt, El Chile perplejo: del avanzar sin transar al transar sin parar, (Santiago de Chile: Planeta/Ariel, 2001).

${ }^{44}$ Ascanio Cavallo C., La Historia oculta de la transición, memoria de una época 1990-1998, Colección crónica histórica (Santiago de Chile: Uqbar Editores, 2013).

${ }^{45}$ Brian Loveman y Elizabeth Lira, El espejismo de la reconciliación política: Chile 1990-2002, Serie historia / LOM Ediciones (Santiago de Chile: LOM Eds. : DIBAM, 2002).

${ }^{46}$ Pinto Vallejos, La historiografía chilena durante el siglo XX. Cien años de propuestas y combates, 107.
} 
mención de Aróstegui: la transición española es la matriz del tiempo presente español, lo cual, tras este estudio, queda confirmada su extensión institucional y académica.

Por su parte, Chile se ve más retrasado en el avance de esta disciplina para estudiar la transición, ya que se ha ralentizado el proceso de incorporación del estudio del pasado reciente a la disciplina histórica, como mencionábamos anteriormente. La poca extensión de la asignatura de Historia Actual nos confirma esta situación. El hecho de que tanto la sociedad chilena como la historiografía hayan tardado en desarrollar el estudio del pasado reciente, se ve reflejado en el hecho de que aún no se ha incorporado como materia en las mallas curriculares de los grados de Historia y Pedagogía.

La anterior afirmación nos lleva a la segunda conclusión, y es que en el caso chileno no existen hasta el momento asignaturas especializadas, ni obligatorias ni optativas, específicamente en el estudio y profundización del proceso de transición. A diferencia del caso español, en el que sí identificábamos algunas optativas que estaban dedicadas exclusivamente al estudio específico de la transición española. En estas asignaturas encontrábamos un alto nivel de especialización en las monografías recomendadas en las guías docentes, identificando por tanto una gran diferencia en el caso chileno en el cual no encontramos este tipo de asignaturas.

Aun así, cabe destacar la interesante implementación efectuada en Chile de la extensión de la asignatura, así como su correspondiente sección en la carrera de Pedagogía, de la Educación Cívica. Elemento significativo y diferenciador con el caso español, ya que hay una voluntad clara desde la administración y los gobiernos chilenos por implementar y fomentar el conocimiento sobre la ciudadanía, la democracia y también su origen. A pesar de que no sea desde un punto de vista específicamente histórico, es necesario identificar esta voluntad por conformar y desarrollar este tipo de educación, que tiene mucho que ver por otra parte con aquella función social de la historia que mencionábamos al inicio.

La cercanía del proceso transicional chileno nos podría hacer pensar que su inclusión en el elenco historiográfico se hará más patente con el paso de los años, pero el hecho de que exista una asignatura dedicada exclusivamente a la formación ciudadana nos hace pensar que la mencionada función social de la historia de formar ciudadanos afines al sistema, y de crear una historia que apuntale el presente, puede verse identificada con esta diferenciación con el caso español.

En todo caso, el elemento en el que sí coinciden tanto España como Chile es en el alto nivel de especialización en el estudio de las transiciones en programas de postgrado 
universitario, donde encontramos másteres oficiales o magísteres que dedican asignaturas íntegramente a este proceso que, además, son dirigidas por investigadores de renombre en el estudio de las transiciones. Este hecho nos da a entender que la especialización y la excelencia del conocimiento histórico que ha alcanzado la historiografía sobre los procesos de transición, en muchos casos, no llega a generalizarse a niveles básicos, quedándose en ambientes y escenarios muy limitados, a los cuales sólo acceden aquellos realmente interesados en el tema.

El desajuste que se identifica entre nivel de especialización en el conocimiento de las transiciones y su expansión en el sistema universitario chileno y español nos hace pensar que efectivamente hay una comunicación y una correlación entre ambos. El ejemplo más significativo es que efectivamente la consolidada historiografía de la transición española y la extensión de estudios sobre Historia Actual ha propiciado que exista una asignatura que se encargue de esta problemática, así como una incipiente extensión de asignaturas específicas sobre los procesos de democratización. Este proceso no se ha dado en las Universidades chilenas, ya que como indicábamos, la evolución historiográfica dista de la española, y su evolución y extensión en las temáticas recientes es todavía muy elemental. De ahí que identificamos una menor presencia de este tipo de asignaturas y sólo una especialización mayor a nivel magíster para el caso de Chile.

Así pues, entendemos que sí existe una conexión entre historiografía y aulas universitarias, pero como hemos comprobado hasta ahora, sí que podría ser más profunda y no sólo quedarse en nivel magister, en el caso chileno o la generalización incipiente de asignaturas específicas de la transición para España. El conocimiento plural que existe de las transiciones, así como la problemática que conlleva acercarse a este proceso histórico, debería ser conocido, al menos, por la totalidad de aquellos que se forman en esta disciplina; ya que da respuestas a nuestro presente, que todo historiador, pero, sobre todo, profesor de historia, debería conocer.

La expansión de un conocimiento más plural que tenga en cuenta la problemática historiográfica bien podría solventarse con revisar los programas universitarios y las mallas curriculares; actualizando y ajustando las asignaturas y los ramos a las nuevas tendencias historiográficas y a los nuevos conocimientos que se van consiguiendo poco a poco con el trabajo investigador de la comunidad académica. Pero más específicamente en los casos del estudio de la transición, lo más beneficioso para un correcto entendimiento de este pasado reciente, de este pasado que está presente, sería la implementación y extensión de una asignatura única, que simulase la de Educación Cívica chilena, para el ámbito universitario: que se enfocase solamente en plantear los debates y la problemática de las transiciones democráticas; 
que comprendiera en su contenido las visiones plurales de las transición; que incluyera la problemática de explicar un proceso histórico tan complejo y reciente; que diera lugar a un acercamiento al sistema democrático actual desde parámetros históricos, pero también críticos; que permitiera, en definitiva, construir un espacio de pensamiento y reflexión sobre el pasado reciente que generase las herramientas intelectuales para formar ciudadanos críticos y concienciados con su papel en el sistema democrático actual, pero también profesores y educares con este perfil.

Entender el pasado reciente que configuró los entresijos de los sistemas democráticos que disfrutamos hoy en día generará la expansión de una perspectiva más abierta y crítica, tanto del pasado, como del presente, en aquellos que se interesan por estudiar el pasado y hacen de él su trabajo, investigándolo, enseñándolo, o simplemente, transmitiéndolo. Además, tener una perspectiva del pasado, abierta y plural, fuera de postulados unívocos, hace que podamos mirar el futuro con nuevas expectativas, e imaginarnos nuevas posibilidades con libertad.

\section{Bibliografía}

Aróstegui Sánchez, Julio. "El presente como historia (La idea de un análisis histórico de nuestro tiempo)". En Actas del Primer Simposio de Historia Actual de La Rioja : Logroño, 14-18 de octubre de 1996, 1996, ISBN 84-89362-14-9, págs. 17-44, 17-44. Instituto Interuniversitario de Desarrollo Social y Paz, 1996.

. La historia vivida: sobre la historia del presente. Madrid: Alianza Editorial, 2004.

Cavallo C., Ascanio. La Historia oculta de la transición, memoria de una época 1990-1998. Santiago de Chile: Uqbar Editores, 2013.

“Consejo de Rectores de las Universidades Chilenas". Accedido 23 de noviembre de 2017. http://www.consejoderectores.cl/historia.

Correa Sutil, Sofía, Consuelo Figueroa, Alfredo Jocelyn-Holt, Claudio Rolle, y Manuel Vicuña. Historia del siglo XX chileno: balance paradojal. Santiago de Chile: Sudamericana, 2001.

“CRUE - Inicio". Accedido 15 de febrero de 2018. http://www.crue.org/SitePages/Inicio.aspx.

Cuesta Bustillo, Josefina. "La historia del tiempo presente: estado de la cuestión". Studia historica. Historia contemporánea, n. ${ }^{0} 1$ (1983): 227-41.

Drake, Paul W., y Iván Jaksic. El difícil camino a la democracia en Chile, 1982-1990. Santiago de Chile: FLACSO, 1993. 
eds. El modelo chileno: democracia y desarrollo en los noventas. Colección Sin Norte. Santiago: LOM Ediciones, 1999.

Gallego, Ferrán. El mito de la transición. La crisis del franquismo y los orígenes de la democracia (1973-1977). Barcelona: Crítica, 2008.

González Ayuso, Yurena. "Transiciones democráticas: Chile y España en perspectiva comparada, 1976-1990”. En Quintas Jornadas de Jóvenes Investigadores de la Universidad de Alcalá: Humanidades y Ciencias Sociales, editado por Cristina Tejedor Martínez, Francisco José Pascual Vives, Germán Ros, Antonio Guerrero Ortega, Jesús Aguado Molina, y Miguel Ángel Hidalgo, 137-46. Alcalá de Henares: Universidad de Alcalá, Servicio de Publicaciones, 2016.

González Martínez, Carmen, y Encarna Nicolás Marín. "Presentación: De la dictadura a la democracia en España y Chile, nuevas perspectivas”. Ayer, Procesos de construcción de la democracia en España y Chile, n. ${ }^{\circ} 79$ (2010): 13-30.

Huneeus Magde, Carlos. El régimen de Pinochet. Santiago de Chile: Editorial Sudamérica, 2001 .

Jenkins, Keith. Repensar la historia. Madrid: Siglo XXI, 2009.

Jocelyn-Holt, Alfredo. El Chile perplejo: del avanzar sin transar al transar sin parar. Santiago de Chile: Planeta/Ariel, 2001.

Linz, Juan J. "La transición española en perspectiva comparada". En Historia de la transición (1975-1986), editado por Javier Tusell y Álvaro Soto Carmona, 21-46. Madrid: Alianza Editorial, 1996.

Lorente Toledo, Luis. "España y el Cono Sur de América Latina. Transiciones y flujo democrático". En Historia de la transición y consolidación democrática en España (1975-1986), II. Perspectiva internacional. Análisis comparado. Política exterior. Economía, sindicatos y sociedad, editado por Javier Tusell y Álvaro Soto Carmona, 3546. Madrid: UNED, UNAM, 1995.

Loveman, Brian, y Elizabeth Lira. El espejismo de la reconciliación política: Chile 1990-2002. Santiago de Chile: LOM Eds. DIBAM, 2002.

Moulián, Tomás. Chile actual. Anatomía de un mito. Santiago de Chile: LOM Ediciones, 1997. 
Muniesa, Bernat. Dictadura y transición. La España lampedusiana. II La monarquía parlamentaria. Barcelona: Universitat de Barcelona, 2005.

Navajas Zubeldía, Carlos. "El regreso de la 'verdadera' historia contemporánea". Revista de historia actual, n. ${ }^{\circ} 1$ (2003): 143-62.

Pinto Vallejos, Julio. La historiografía chilena durante el siglo XX. Cien años de propuestas y combates. Valparaíso: América en Movimiento Editorial, 2016.

Rouquié, Alain. A la sombra de las dictaduras. La democracia en América Latina. Buenos Aires: Fondo de Cultura Económica, 2011.

Sánchez Delgado, Primitivo. "El valor de la historia y los valores en la enseñanza de la historia". Revista complutense de educación 2, n. ${ }^{\circ} 2$ (1991): 309-22.

S.A.P, El Mercurio. "Bachelet promulga ley que introduce la formación cívica en todos los colegios del país | Emol.com”. Emol, 28 de marzo de 2016. http://www.emol.com/noticias/Nacional/2016/03/28/795187/Bachelet-promulga-leyque-incluye-la-formacion-ciudadana-en-los-colegios.html.

Soto Carmona, Álvaro. "Diálogos y encuentros”. En Chile y España diálogos y encuentros, de Joaquín Almunia y Genaro Arriagada. Aguilar, 2002.

—_. "Ni modélica ni fracasada. La transición a la democracia en España: 1975-1982”. Indice histórico español, n. ${ }^{\circ} 125$ (2012): 117-56.

—. Transición y cambio en España, 1975-1996. Madrid: Alianza Editorial, 2005.

Soto Gamboa, Ángel. El presente es historia: reflexiones de teoría y método. Santiago de Chile: Eds. Centro de Estudios Bicentenario : CIMAS, Facultad de Comunicación Universidad de Los Andes, 2006.

Soto Gamboa, Angel. “QQué es la historia del presente? Un intento de conceptualización”. Información pública, n. $^{\circ} 2$ (2003): 534-38.

Tusell Gómez, Javier. Dictadura franquista y democracia, 1939-2004. Barcelona: Crítica, 2005.

\section{—. La transición española a la democracia. Madrid: Historia 16, 1997.}

Vallespín, Fernando. “QQué le pasa a la universidad española?” EL PAÍS, 20 de agosto de 2017. https://elpais.com/elpais/2017/08/19/opinion/1503161501_791914.html. 
Anexo I: Universidades y páginas webs.

\begin{tabular}{|c|c|}
\hline Universidades Españolas & - Páginas web \\
\hline UNED & $\begin{array}{l}\text { http://portal.uned.es/portal/page? pageid=93,1\& d } \\
\text { ad=portal\& schema=PORTAL }\end{array}$ \\
\hline Universidad Autonoma de Barcelona & http://www.uab.cat/ \\
\hline Universidad Autónoma de Madrid & http://www.uam.es/UAM/Home.htm?language=es \\
\hline Universidad Complutense & https://www.ucm.es/ \\
\hline Universidad de Alcalá de Henares & https://www.uah.es/es/ \\
\hline Universidad de Cádiz & http://www.uca.es/ \\
\hline Universidad de Cantabria & http://web.unican.es/ \\
\hline Universidad de Castilla-La Mancha & https://www.uclm.es/ \\
\hline Universidad de Córdoba & http://www.uco.es/ \\
\hline Universidad de Deusto & $\begin{array}{l}\text { http://www.deusto.es/cs/Satellite/deusto/es/univers } \\
\text { idad-deusto }\end{array}$ \\
\hline Universidad de Extremadura & https://www.unex.es/ \\
\hline Universidad de Huelva & http://www.uhu.es/index.php \\
\hline Universidad de Jaén & http://www10.ujaen.es/ \\
\hline Universidad de la Coruña & https://www.udc.es/?language=es \\
\hline Universidad de La Rioja & http://www.unirioja.es/ \\
\hline Universidad de León & https://www.unileon.es/ \\
\hline Universidad de Málaga & https://www.uma.es/ \\
\hline Universidad de Murcia & http://www.um.es/ \\
\hline Universidad de Navarra & https://www.unav.edu/ \\
\hline Universidad de Oviedo & http://www.uniovi.es/ \\
\hline Universidad de Salamanca & http://www.usal.es/ \\
\hline Universidad de Santiago de Compostela & http://www.usc.es/ \\
\hline Universidad de Sevilla & http://www.us.es/ \\
\hline Universidad de Valencia & $\begin{array}{l}\text { https://www.uv.es/uvweb/universidad/es/universid } \\
\underline{\text { ad-valencia-1285845048380.html }}\end{array}$ \\
\hline Universidad de Valladolid & http://www.uva.es/export/sites/uva/ \\
\hline Universidad de Vigo & https://uvigo.gal/ \\
\hline Universidad de Zaragoza & https://www.unizar.es/ \\
\hline Universidad del País Vasco & https://www.ehu.eus/es/ \\
\hline Universidad Rey Juan Carlos & https://www.urjc.es/ \\
\hline Universitat de Barcelona & http://www.ub.edu/web/ub/ca/ \\
\hline Universitat de Girona & https://www.udg.edu/ca/ \\
\hline Universitat de Lleida & http://www.udl.cat/ca/es/ \\
\hline Universitat Pompeu Fabra & https://www.upf.edu/es/ \\
\hline Universitat Ramon Llull & http://www.url.edu/es \\
\hline Universitat Rovira i Virgili & http://www.urv.cat/es/ \\
\hline
\end{tabular}

Fuente: elaboración propia. 
Universidades chilenas

Pontificia Universidad Católica de Chile

Pontificia Universidad Católica de Valparaíso

Universidad Adolfo Ibáñez

Universidad Alberto Hurtado

Universidad Andrés Bello

Universidad Arturo Prat

Universidad Austral de Chile

Universidad Autónoma de Chile

Universidad Bernador O'Higgins

Universidad Católica de la Santísima Concepción

Universidad Católica de Temuco

Universidad Católica del Maule

Universidad Católica del Norte

Universidad de Antofagasta

Universidad de Atacama

Universidad de Aysén

Universidad de Chile

Universidad de Concepción

Universidad de la Frontera

Universidad de la Serena

Universidad de los Andes

Universidad de Los Lagos

Universidad de Magallanes

Universidad de O'Higgins

Universidad de Playa Ancha de Ciencias de la Educación

Universidad de Santiago de Chile

Universidad de Talca

Universidad de Tarapacá

Universidad de Valparaíso

Universidad del Bio Bio

Universidad Diego Portales

Universidad Metropolitana de Ciencias de la Educación

Universidad San Sebastían

Universidad Técnica Federico Santa María

Universidad Tecnológica Metropolitana

Fuente: elaboración propia.

\section{† Páginas webs}

http://www.uc.cl/

http://www.ucv.cl/

http://admision.uai.cl/

http://www.uahurtado.cl/

http://www.unab.cl/

http://www.unap.cl/prontus unap/site/

edic/base/port/inicio.html

http://www.uach.cl/

http://www.uautonoma.cl/

http://www.ubo.cl/

http://www.ucsc.cl/

https://uct.cl/

http://www.ucm.cl/

http://www.ucn.cl/

http://www.uantof.cl/

http://www.uda.cl/

http://http//www.uaysen.cl/

http://www.uchile.cl/

http://www.udec.cl/pexterno/

http://www.ufro.cl/

http://www.userena.cl/

http://www.uandes.cl/

http://www.ulagos.cl/

http://www.umag.cl/

http://www.uoh.cl/

http://www.upla.cl/portada/

http://www.usach.cl/

http://www.utalca.cl/link.cgi/\#/link.cgi/

http://www.uta.cl/

http://www.uv.cl/

http://www.ubiobio.cl/w/

http://www.udp.cl/

http://www.umce.cl/

http://www.uss.cl/

http://www.utfsm.cl/

http://www.utem.cl/ 


\section{Anexo II: Tabla Universidades chilenas}

\begin{tabular}{|c|c|c|c|c|c|c|}
\hline № & Universidades Consultadas & $\begin{array}{l}\text { Carrera de } \\
\text { Historia }\end{array}$ & Carrera & $\begin{array}{l}\text { Acceso a } \\
\text { Guía } \\
\text { Docente }\end{array}$ & Asignaturas Interesantes & $\begin{array}{l}\text { Historia } \\
\text { Actual }\end{array}$ \\
\hline 1 & Universidad de Tarapacá & No & - & No & - & No \\
\hline 2 & Universidad Católica del Norte & No & - & No & - & No \\
\hline 3 & Universidad de la Frontera & Sí & $\begin{array}{l}\text { Pedagogía en Historia, Geografía y } \\
\text { Educación Cívica }\end{array}$ & No & $\begin{array}{l}\text { Historia de Chile Siglo XX; Historia Constitucional } \\
\text { y Política de Chile }\end{array}$ & No \\
\hline 4 & Universidad Arturo Prat & No & - & No & - & No \\
\hline 5 & Universidad de Antofagasta & No & - & No & - & No \\
\hline 6 & Universidad de la Serena & Sí & Pedagogía en Historia y Geografía & No & Chile en el Siglo XX & No \\
\hline 7 & Universidad de Playa Ancha & Sí & Pedagogía en Historia y Geografía & No & $\begin{array}{l}\text { Historia de Chile siglo XX. Crisis, democracia y } \\
\text { desarrollo }\end{array}$ & No \\
\hline 8 & Universidad de Atacama & No & - & & - & No \\
\hline 9 & $\begin{array}{l}\text { Universidad Metropolitana de Ciencias } \\
\text { de la Educación }\end{array}$ & Sí & $\begin{array}{l}\text { Licenciatura en Educación con Mención en } \\
\text { Historia o Geografía y Pedagogía en } \\
\text { Historia, geografía y Educación Cívica }\end{array}$ & No & Historia de Chile IV: Segunda Mitad del Siglo XX & No \\
\hline 10 & Universidad de Magallanes & Sí & Pedagogía en Historia y Ciencias Sociales & No & - & No \\
\hline 11 & Universidad del Bio-Bio & Sí & Pedagogía en Historia y Geografía & No & Historia de Chile del Siglo XX & No \\
\hline 12 & Universidad de Los Lagos & Sí & $\begin{array}{l}\text { Pedagogía en Educación media en Historia y } \\
\text { Geografía }\end{array}$ & No & No & No \\
\hline 13 & $\begin{array}{l}\text { Universidad Católica de la Santísima } \\
\text { Concepción }\end{array}$ & Sí & Licenciatura en Historia & No & Chile Siglo XX & No \\
\hline 14 & Universidad de Talca & No & - & No & - & No \\
\hline 15 & Universidad Católica del Maule & No & - & No & - & No \\
\hline 16 & Universidad de Concepción & Sí & Licenciatura en Historia & No & Historia de Chile siglo XX y XXI & No \\
\hline 17 & Universidad de Concepción & Sí & Pedagogía en Historia & No & $\begin{array}{l}\text { Historia Actual: globalización e identidades } \\
\text { locales }\end{array}$ & Sí \\
\hline 18 & Pontificia Universidad Católica de Chile & Sí & Licenciatura en Historia & No & Historia de Chile Contemporáneo & No \\
\hline 19 & Universidad Andrés Bello & Sí & Licenciatura en Historia & Sí & Chile en el Siglo XX, Chile Actual & Sí \\
\hline 20 & Universidad Austral de Chile & Sí & Pedagogía en Historia y Ciencias Sociales & Sí & Historia de Chile Siglo XX; Chile Reciente & Sí \\
\hline 21 & Universidad de Santiago de Chile & Sí & Licenciatura en Historia & No & Historia de Chile Contemporáneo & No \\
\hline 22 & Universidad de Chile & Sí & Licenciatura en Historia & No & Historia de Chile Contemporáneo & No \\
\hline 23 & $\begin{array}{l}\text { Pontificia Universidad Católica de } \\
\text { Valparaíso }\end{array}$ & Sí & $\begin{array}{l}\text { Licenciatura en Historia con Mención en } \\
\text { Ciencia Política }\end{array}$ & Sí & Historia de Chile Contemporáneo I y II & No \\
\hline 24 & $\begin{array}{l}\text { Pontificia Universidad Católica de } \\
\text { Valparaíso }\end{array}$ & Sí & $\begin{array}{l}\text { Pedagogía en Historia, Geografía y Ciencias } \\
\text { Sociales }\end{array}$ & No & Historia de Chile Contemporáneo I y II & No \\
\hline 25 & Universidad de Valparíso & Sí & Pedagogía en Historia y Ciencias Sociales & No & Historia de Chile Siglo XX & No \\
\hline 26 & Universidad Autónoma de Chile & Sí & $\begin{array}{l}\text { Pedagogía en Historia, Geografía y Ciencias } \\
\text { Sociales }\end{array}$ & No & Historia de América y Chile Contemporánea I y II & No \\
\hline 27 & Universidad Diego Portales & Sí & Licenciatura en Historia & No & Chile Siglo XX & No \\
\hline 28 & Universidad Adolfo Ibánez & No & - & No & - & No \\
\hline 29 & Universidad de los Andes & Sí & Licenciatura en Historia & No & $\begin{array}{l}\text { Historia de Chile Contemporáneo (1891-1960) e } \\
\text { Historia de Chile Reciente }\end{array}$ & Sí \\
\hline 30 & Universidad Católica de Temuco & Sí & $\begin{array}{l}\text { Pedagogía en Historia, Geograía y Ciencias } \\
\text { Sociales }\end{array}$ & No & América y Chile en los siglos XX y XXI & No \\
\hline 31 & Universidad San Sebastían & Sí & $\begin{array}{l}\text { Pedagogía en Educación media en Historia y } \\
\text { Geografía }\end{array}$ & No & Chile Siglo XX & No \\
\hline 32 & Universidad Alberto Hurtado & Sí & Licenciatura en Historia & No & Chile Independiente II & No \\
\hline 33 & $\begin{array}{l}\text { Universida Santo Tomás Santiago de } \\
\text { Chile }\end{array}$ & No & - & No & - & No \\
\hline 34 & Universidad Bernador O'Higgins & Sí & Pedagogía en Historia y Geografía & No & Historia de Chile y América Contemporáneo I, II & No \\
\hline 35 & Universidad de las Américas & Sí & $\begin{array}{l}\text { Pedagogía en Historia, Geografía y } \\
\text { Educación Cívica }\end{array}$ & No & $\begin{array}{l}\text { Historia de Chile Contemporáneo; Educación } \\
\text { cívica y ciudadanía. }\end{array}$ & No \\
\hline
\end{tabular}

Fuente: elaboración propia. 
TEMPUS Revista en Historia General Medellín (Colombia), 2018, Primer Semestre, Número 7 Pp. 135-166, ISSN: 2422-2178 (En línea)

\section{Anexo III: Tabla Universidades españolas}

\begin{tabular}{|c|c|c|c|c|c|c|c|}
\hline № & Universidad & $\begin{array}{l}\text { Carrera de } \\
\text { Historia }\end{array}$ & Carrera & $\begin{array}{l}\text { Aceeso a Guía } \\
\text { Docente }\end{array}$ & Asinaturas interesantes & $\begin{array}{l}\text { Asignaturas de } \\
\text { Hisotira Actual }\end{array}$ & Nombre Asignatura \\
\hline 1 & Universidad Complutense & Sí & Grado en Historia & Sí & Historia de España Contemporánea Siglo XX & Sí & Historia del Tiempo Presente \\
\hline 2 & $\begin{array}{l}\text { Universidad Autónoma de } \\
\text { Madrid }\end{array}$ & Sí & Grado en Historia & Sí & $\begin{array}{l}\text { Optativas: Dictadura y Democracia en el siglo XX } \\
\text { Español }\end{array}$ & Sí & Historia del Mundo Actual \\
\hline 3 & $\begin{array}{l}\text { Universidad de Alcalá de } \\
\text { Henares }\end{array}$ & Sí & Grado en Historia & Sí & Historia de España Contemporánea Siglo XX & Sí & $\begin{array}{l}\text { Historia del Mundo Actual y España } \\
\text { Actual (Bibliografía sin tema transición) }\end{array}$ \\
\hline 4 & Universidad Rey Juan Carlos & Sí & Grado en Historia & No & $\begin{array}{l}\text { Historia de España Contemporánea Siglo XX, } \\
\text { Historia España Actual }\end{array}$ & Sí & Historia de España Actual \\
\hline 5 & UNED & sí & Grado en Geografía e Historia & Sí & $\begin{array}{l}\text { Historia de España Contemporánea II, desde 1923; } \\
\text { La transición a la democracia en España }\end{array}$ & No & - \\
\hline 6 & $\begin{array}{l}\text { Universidad Autonoma de } \\
\text { Barcelona }\end{array}$ & Sí & Grado en Historia & Sí & $\begin{array}{l}\text { Història Contemporània d'Espanya III, el } \\
\text { Franquisme i la Democràcia; Història } \\
\text { Contemporània de Catalunya II, el Franquisme i la } \\
\text { Recuperació de l'Autonomia }\end{array}$ & No & - \\
\hline 7 & Universitat de Barcelona & $\mathrm{Si}$ & Grado en Historia & No & $\begin{array}{l}\text { Història Contemporània d'Espanya; Història } \\
\text { Contemporània de Catalunya II }\end{array}$ & Sí & Mon Actual \\
\hline 8 & 3 Universitat Ramon Llull & No & - & No & - & No & - \\
\hline 9 & Universitat de Lleida & $\mathrm{Si}$ & Grado en Historia & No & $\begin{array}{l}\text { Historia Contemporánea de España; Histoia } \\
\text { Contemporánea de Cataluña; Mundo Actual }\end{array}$ & Sí & Mundo Actual \\
\hline 10 & Universitat de Girona & Sí & Grado en Historia & No & Historia de España y Cataluña & No & - \\
\hline 11 & Universitat Pompeu Fabra & No & - & No & - & No & - \\
\hline 12 & Universidad de Murcia & Si & Grado de Historia & Sí & Historia Contemporánea de España. & No & - \\
\hline 13 & Universidad de Valencia & Sí & Grado en Historia & Sí & Historia Contemporánea de España II & No & - \\
\hline 14 & Universidad de Málaga & $\mathrm{Si}$ & Grado en Historia & No & $\begin{array}{l}\text { Historia Contemporánea de España; Historia de } \\
\text { Andalucia en la Edad Contemporánea } \\
\text { (Complementaria) }\end{array}$ & No & - \\
\hline 15 & Universidad de Sevilla & Sí & Grado en Historia & No & $\begin{array}{l}\text { Historia Contemporánea de España; Historia de } \\
\text { Andalucia Contemporánea (Optativa) }\end{array}$ & Sí & $\begin{array}{l}\text { Historia del Mundo Actual; Historia de } \\
\text { España Actual }\end{array}$ \\
\hline 16 & Universidad de Cádiz & Sí & Grado en Historia & Sí & $\begin{array}{l}\text { Historia Contemporánea de España; Historia, } \\
\text { Ciudadania y Democracia en el Mundo } \\
\text { Contemporáneao (Optativa) }\end{array}$ & No & 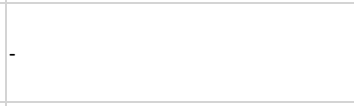 \\
\hline 17 & Universidad de Córdoba & Sí & Grado en Historia & Sí & Historia Contemporánea de España; & Sí & $\begin{array}{l}\text { Historia del Mundo Actual; Historia de } \\
\text { España Actual (Optativa) }\end{array}$ \\
\hline 18 & 3 Universidad de Salamanca & $\mathrm{Si}$ & Grado en Historia & Sí & $\begin{array}{l}\text { Historia Contemporánea Comparada de España y } \\
\text { Portugal; }\end{array}$ & No & 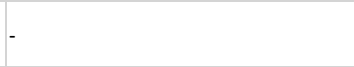 \\
\hline 19 & Universidad de Extremadura & Sí & Grado en Historia & Sí & Historia Contemporánea de España & Sí & $\begin{array}{l}\text { Mundo Actual e Historia del Tiempo } \\
\text { Presente; Historia de España Actual }\end{array}$ \\
\hline 20 & Universidad de Valladolid & Sí & Grado en Historia & Sí & $\begin{array}{l}\text { Historia Social de la España Contemporánea; } \\
\text { Historia Contemporánea II; }\end{array}$ & Sí & Historia del Mundo Actual \\
\hline 21 & Universidad de Zaragoza & Sí & Grado de Historia & Sí & $\begin{array}{l}\text { Historia de España Contemporánea: siglo XX; } \\
\text { Historia de los movimientos sociales } \\
\text { contemporáneos }\end{array}$ & Sí & Historia del Mundo Actual \\
\hline 22 & Universidad de Navarra & Sí & Grado en Historia & No & Historia de España siglo XX & Sí & Claves del Mundo Actual I y II \\
\hline 23 & Universidad de La Rioja & Sí & Grado en Geografía e Historia & Sí & $\begin{array}{l}\text { Historia Contemporánea de España; Historia de las } \\
\text { ideas y movimientos sociales contemporáneos }\end{array}$ & No & - \\
\hline 24 & Universidad del País Vasco & Sí & Grado en Geografía e Historia & Sí & $\begin{array}{l}\text { Historia Contemporánea del País Vasco; NO } \\
\text { Historia Contemporánea de España; La práctica de } \\
\text { la Historia Contemporánea }\end{array}$ & Sí & Historia del Mundo Actual (Optativa); \\
\hline 25 & Universidad de Deusto & NO & $\begin{array}{l}\text { Grado en Filosofía, Política y } \\
\text { Economía }\end{array}$ & No & 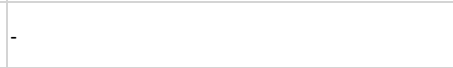 & No & - \\
\hline 26 & Universidad de Cantabria & Sí & Grado en Historia & Sí & Historia Contemporánea de España II & Sí & Historia del Tiempo Presente \\
\hline 27 & Universidad de Oviedo & Sí & Grado en Historia & Sí & $\begin{array}{l}\text { Historia Contemporánea de España; Historia } \\
\text { Contemporánea de Asturias }\end{array}$ & Sí & España y el Mundo Actual \\
\hline 28 & 3 Universidad de León & Sí & Grado en Historia & Sí & $\begin{array}{l}\text { Historia de España Contemporánea II: del reinado } \\
\text { de Alfonso XIII a nuestros días; }\end{array}$ & No & - \\
\hline 29 & Universidad de la Coruña & No & Grado en Humanidades & Sí & Historia Contemporánea de España & No & - \\
\hline 30 & Universidad de Vigo & Sí & Grado en Geografía e Historia & Sí & $\begin{array}{l}\text { Historia Contemporánea de España; Historia } \\
\text { Contemporánea de Galicia }\end{array}$ & Sí & Mundo Actual \\
\hline 31 & $\begin{array}{l}\text { Universidad de Santiago de } \\
\text { Compostela }\end{array}$ & Sí & Grado en Historia & No & $\begin{array}{l}\text { Historia Contemporánea de España I y II; Historia } \\
\text { de Galicia I, II y III; }\end{array}$ & No & - \\
\hline 32 & Universidad de Jaén & Sí & Grado en Geografía e Historia & Sí & $\begin{array}{l}\text { Historia contemporánea de los países } \\
\text { mediterráneos; Historia contemporánea y actual } \\
\text { de España }\end{array}$ & Sí & $\begin{array}{l}\text { Historia contemporánea y actual de } \\
\text { España }\end{array}$ \\
\hline 33 & Universidad de Huelva & Sí & Grado en Historia & Sí & Historia Contemporánea de España & Sí & Historia de España Actual (Optativa) \\
\hline 34 & Universitat Rovira i Virgili & Sí & $\begin{array}{l}\text { Licenciatura en Historia (en } \\
\text { extinción) }\end{array}$ & No & $\begin{array}{l}\text { Història Contemporànea de Catalunya; No historia } \\
\text { de España }\end{array}$ & Sí & El Mon Actual I y II \\
\hline 35 & $\begin{array}{l}\text { Universidad de Castilla-La } \\
\text { Mancha }\end{array}$ & Sí & Grado en Historia & No & $\begin{array}{l}\text { España Contemporánea entre dictaduras y } \\
\text { democracia; }\end{array}$ & Sí & $\begin{array}{l}\text { Mundo Actual: Sociedades, economías, } \\
\text { culturas }\end{array}$ \\
\hline
\end{tabular}

Fuente: elaboración propia 


\section{Anexo IV: Gráficas}

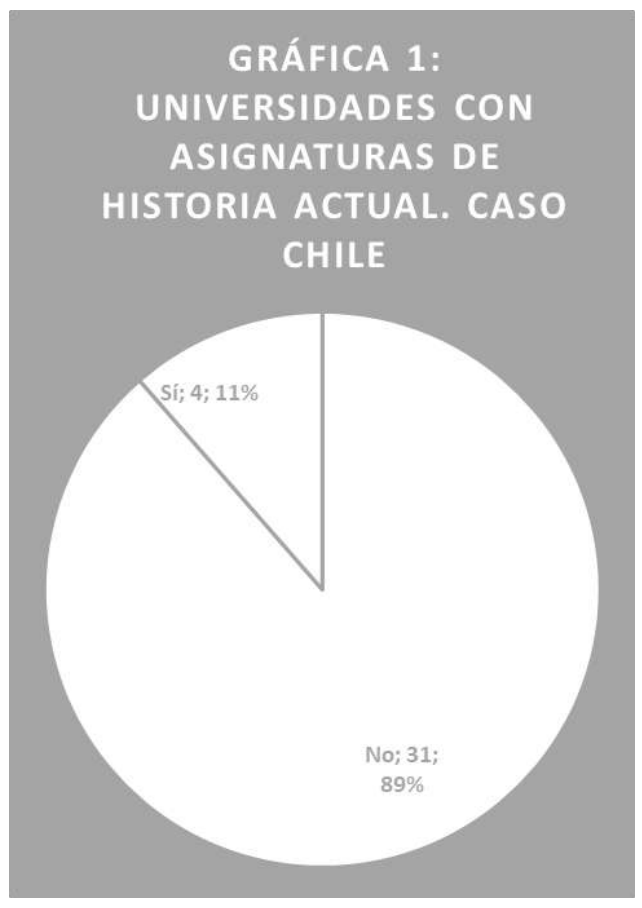

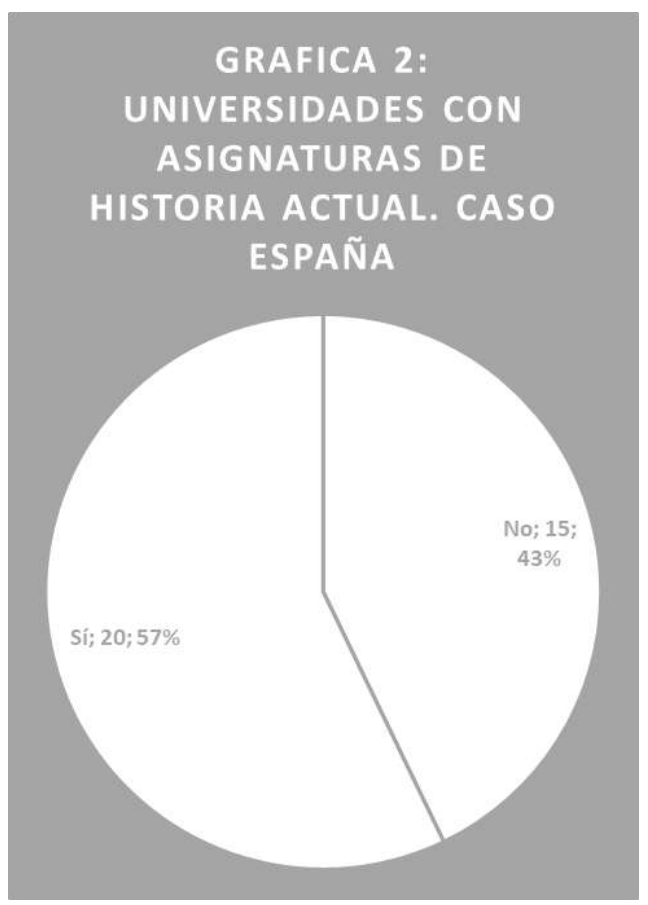

Gráfica 3. Monografías más utilizadas España

Maravall. La política de la transición 1975-1980

Quirosa-Cheyrouze. La sociedad española en la Transición

Powell. España en democracia, 1975-2000

Redero San Román. La transición a la democracia en España, Ayer

Tusell. La transición a la democracia y el reinado de Juan Carlos I, en...

Cotarelo. Transición política y consolidación democrática en España...

Soto Carmona y Tusell (eds.), Historia de la transición

Varios Autores. Historia de la España Actual 1939-2000....

Ruiz González. La España democrática (1975-2000): política y sociedad

Tusell. Dictadura franquista y democracia, 1939-2004

Gallego. El mito de la transición: la crisis del franquismo y los...

Tusell. La transición española a la democracia

Muniesa. Dictadura y monarquía en España. De 1939 hasta la...

Soto Carmona. Transición y cambio en España 1975-1996
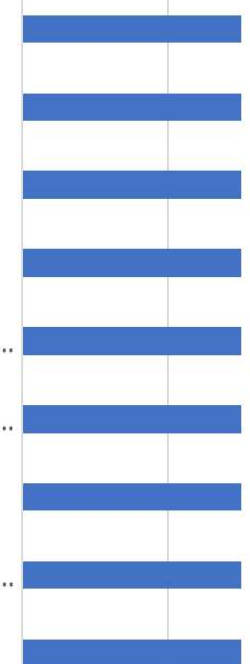

4

6

Fuente: elaboración propia. 
TEMPUS Revista en Historia General

Gráfica 4. Monografías más utilizadas. Chile

Hidalgo. El ciclo político de la Concertación

Varas. La democracia frente al poder. Chile 1990-2010

Cañas Kirby. Proceso político en Chile 1973-1990

Muñoz. Transición a la democracia, marco político y...

Portales. Chile: una democracia tutelada

Boeninger. Democracia en Chile: lecciones para la...

Loveman y Lira. El espejismo de la reconciliación política..

Cavallo. Historia oculta de la transición. Memoria de una...

Jocelyn-Holt. El Chile perplejo. Del avanzar sin transar al...

Drake y Jaksic. El difícil camino a la democracia en Chile

Drake y Jaksic (Comps.). El modelo chileno. Democracia y..

Varios Autores. Historia del siglo XX chileno

Moulián. Chile actual. Anatomia de un mito

Huneeus. El régimen de Pinochet
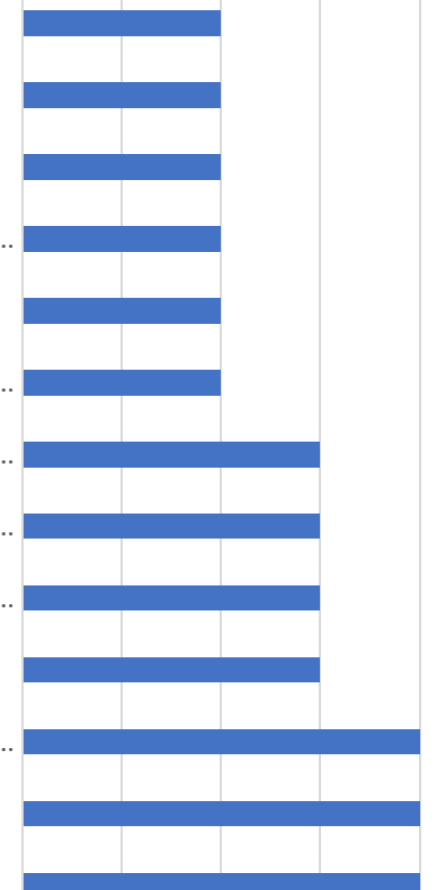

$\begin{array}{lllllllll}0 & 1 & 2 & 3 & 4 & 5 & 6 & 7 & 8\end{array}$

Fuente: elaboración propia.

Fuente: elaboración propia. 


\begin{tabular}{|c|c|c|}
\hline Asignaturas consultadas y la bibliografía aportada en la guía docente sobre la transición & Chile & paña \\
\hline Historia de España Actual & & 14 \\
\hline Historia de España Contemporánea & & 14 \\
\hline Democracias y Dictaduras en la España del siglo XX & & 10 \\
\hline El Estado y el espacio público. Transiciones a la democracia en el siglo XX & & 10 \\
\hline Historia Contemporánea III, el Franquismo y la democracia & & 7 \\
\hline España y el Mundo Actual & & 5 \\
\hline Políticas de memoria y transiciones a la democracia & & 5 \\
\hline España Contemporánea entre dictaduras y democracia & & 4 \\
\hline Historia Contemporánea de España siglo XX & & 4 \\
\hline Historia Contemporánea de España & & 3 \\
\hline Historia de la España Actual & & 3 \\
\hline Historia del Mundo Actual & & 3 \\
\hline La democracia en el Mundo Occidental: Procesos de Construcción & & 3 \\
\hline La transición a la democracia en España & & 3 \\
\hline Historia Contemporánea de España II & & 2 \\
\hline Historia de España Contemporánea siglo XX & & 2 \\
\hline Historia Contemporánea de España II: desde 1923 & & 1 \\
\hline $\begin{array}{l}\text { Los nudos históricos de la transición chilena a la democracia. Actores y coyunturas políticas } \\
(1983-1998)\end{array}$ & 19 & \\
\hline Chile Actual & 15 & \\
\hline Chile Reciente & 12 & \\
\hline Historia De Chile Contemporáneo & 6 & \\
\hline Historia de Chile Contemporáneo: segunda mitad del siglo XX & 5 & \\
\hline Autoritarismo y Democracia & 3 & \\
\hline Historia de Chile, Siglo XX & 2 & \\
\hline
\end{tabular}

Fuente: elaboración propia. 